\title{
Estágio supervisionado em terapia ocupacional em um centro de atençáo psicossocial CAPS II: Desafios para a assistência e para o processo de ensino-aprendizagem
}

\author{
Milton Carlos Mariotti ${ }^{a}$, Luciana Carvalho Marques ${ }^{\mathrm{b}}$, Aline Schlean ${ }^{\mathrm{b}}$, Rafaela Silva ${ }^{\mathrm{b}}$, \\ Diane Priscila Stoffel ${ }^{\mathrm{b}}$, Bruna Veiga $^{\mathrm{c}}$
}

\author{
${ }^{a}$ Departamento de Terapia Ocupacional, Universidade Federal do Paraná - UFPR, Curitiba, PR, Brasil

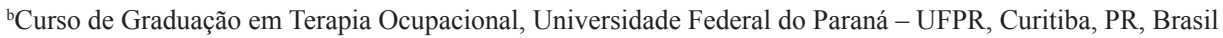 \\ ${ }^{\mathrm{c}}$ Centro de Atenção Psicossocial - CAPS II, Curitiba, PR, Brasil
}

\begin{abstract}
Resumo: A reforma psiquiátrica no Brasil substituiu o modelo hospitalocêntrico pela proposta de reinserção do usuário na comunidade, sendo o Centro de Atenção Psicossocial (CAPS) o principal equipamento nesse âmbito. Objetivos: Relatar o desenvolvimento de um Estágio Supervisionado de Prática em Terapia Ocupacional num CAPS II de Curitiba. Procedimentos metodológicos: Trata-se de um relato de experiência. Caracteriza o campo de estágio e descreve as etapas do processo de ensino-aprendizagem que envolveu: observação institucional, relatório dos aspectos observados, proposta de intervenção, coleta de dados do perfil dos usuários e atendimentos. $\mathrm{O}$ foco do trabalho foi o grupo de usuários do regime não intensivo, por estarem mais próximos da alta, considerando-se a falta de equipamentos para a continuidade da assistência para essa população. Resultados: Observou-se que os usuários do regime não intensivo, ao invés de almejarem a alta, gostariam de retornar aos regimes semi-intensivo ou intensivo, objetivando recuperar direitos ao auxílio-doença e transporte, o que denota grande contradição no sistema. Foram atendidos complementarmente também usuários dos regimes intensivo e semi-intensivo. Conclusões: O aprendizado dos estudantes contemplou aspectos como: a realidade institucional; conhecimento do sistema de saúde, suas limitações e contradições; aproximação com usuários, familiares, suas condições socioeconômicas, desejos, aspirações ou sua falta, dificuldades para engajamento em ocupações significativas em seu território, limitações e estigmas sociais; trabalho com as frustrações, reflexão sobre as possibilidades de mudança da realidade, além da prática clínica ampliada com discussões sobre os modelos de intervenção e os de formulação das políticas públicas de assistência à saúde mental e controle social.
\end{abstract}

Palavras-chave: Terapia Ocupacional, Serviços Comunitários de Saúde Mental, Prática Profissional.

\section{Supervised practice in occupational therapy in a psychosocial care center: Challenges for the assistance and the teaching and learning process}

\begin{abstract}
The psychiatric reform in Brazil has replaced the hospital-centered model by the reintegration of users to their respective communities. The Center of Psychosocial Care (CAPS) has been the main equipment in that scope. Objectives: To report the development of Supervised Practice in Occupational Therapy in a CAPS II unit in Curitiba, Parana state, Brazil. Methods: This is an experience report. It features the training field and describes the stages of the teaching and learning process which involved institutional observation, reporting and intervention proposal, collecting data about the users' profile and attendances. The work focused the non-intensive users because they are close to hospital discharge. Results: We found that users of the non-intensive system, rather than crave the discharge, would like to return to the semi-intensive or intensive systems, aiming to regain sickness and transportation
\end{abstract}

Autor para correspondência: Milton Carlos Mariotti, Departamento de Terapia Ocupacional, Universidade Federal do Paraná - UFPR, Av. Lothário Meissner, 632, Bloco Didático II, Setor de Ciências da Saúde, Campus Jardim Botânico, CEP 80210-170, Curitiba, PR, Brasil, e-mail: mariotti@ufpr.br

Recebido em 11/6/2012; $1^{\text {a }}$ Revisão em 10/9/2012; $2^{a}$ Revisão em 21/10/2012; Aceito em 7/11/2012. 
benefits, which are lost as users make progress. This fact denotes great contradictions in the system. We also attended intensive and semi-intensive systems users. Conclusions: The students' learning included aspects such as direct contact with the institutional reality; knowledge about the health system, its limitations and contradictions; approach to users, their families, realities, socioeconomic conditions, desires, aspirations, or lack thereof; difficulties in engaging in meaningful occupations in their territories, limitations, and social stigma; working with frustrations, reflecting about ways to change the reality; in addition to expanded clinical practice, participating in the discussions and formulation of public policies on mental healthcare and social control.

Keywords: Occupational Therapy, Community Mental Health Services, Professional Practice.

\section{Introdução}

Neste trabalho, o foco foi o Centro de Atenção Psicossocial - (CAPS) II, local em que a experiência relatada foi desenvolvida, em especial o grupo de usuários do regime não intensivo, por estarem mais próximos da alta e pela carência de equipamentos para a continuidade de sua assistência. A fundamentaçáo teórica, conceituação e descrição do CAPS foram construídas a partir de documento do Ministério da Saúde de 2004, por ser um documento oficial e bastante completo a respeito do assunto.

A reforma psiquiátrica trouxe mudanças consideráveis para a Atenção em Saúde Mental no Brasil, propondo a substituição do modelo hospitalocêntrico por um modelo voltado para a reinserção do usuário na comunidade. Para isso foram criados os serviços substitutivos ao internamento em hospital psiquiátrico como os (CAPS), as Residências Terapêuticas e os Centros de Convivência (HIRDES, 2009).

Dentre esses equipamentos destaca-se o CAPS - principal equipamento desse modelo substitutivo. No Brasil, o primeiro deles foi inaugurado em São Paulo, no ano de 1986 (BRASIL, 2004).

Os CAPS foram criados oficialmente a partir da portaria GM 224/92 (BRASIL, 1992) e hoje são regulamentados pela portaria n. 336/GM, de 19 de fevereiro de 2002 (BRASIL, 2002). Integram o Sistema Único de Saúde (SUS), sendo definidos como locais de referência e tratamento a pessoas com transtornos mentais graves, que necessitem de atenção intensiva, personalizada e prestada junto à comunidade na qual a pessoa está inserida (BRASIL, 2004). Assim, a implantação dos CAPS visa

[...] oferecer atendimento à população de sua área de abrangência, realizando o acompanhamento clínico e a reinserção social dos usuários pelo acesso ao trabalho, lazer, exercício dos direitos civis e fortalecimento dos laços familiares e comunitários. É um serviço de atendimento de saúde mental criado para ser substitutivo às internaçōes em hospitais psiquiátricos (BRASIL, 2004, p. 13).
Nesse sentido, cabe a tais equipamentos oferecer atendimentos diários aos usuários residentes em sua área de abrangência, com projetos terapêuticos singulares para cada usuário atendido. As açôes desenvolvidas pelas equipes multiprofissionais que compóem os CAPS devem possibilitar a estruturação de estratégias para o enfrentamento de problemas junto aos usuários, especialmente por meio de açôes intersetoriais, ou seja, que articulem a saúde com setores como educação, trabalho, cultura, assistência social e outros (BRASIL, 2004).

A região Sul do Brasil é a que apresenta maior número de CAPS por 100 mil habitantes (BRASIL, 2004); existindo 27 na regiăo Norte, 109 na regiáo Nordeste, 29 na região Centro-oeste, 240 na região Sudeste e 111 na região Sul.

De acordo com o Ministério da Saúde (BRASIL, 2004), um dos maiores desafios da reforma psiquiátrica está relacionado à consolidação desses serviços substitutivos aos hospitais psiquiátricos. Após 10 anos, a implantação dos CAPS tem se mostrado uma estratégia eficaz no sentido da substituiçáo do modelo hospitalocêntrico de atenção a pessoas com transtornos mentais.

A frequência do usuário no CAPS depende de suas necessidades, podendo ocorrer nas modalidades de atendimento intensivo, semi-intensivo e não intensivo, nas quais o usuário é atendido no CAPS diariamente, três vezes por semana ou três vezes no mês, respectivamente (BRASIL, 2004). As diferentes modalidades são destinadas aos usuários em diferentes fases, manifestaçóes e de acordo com a gravidade dos quadros de transtorno mental apresentados, como também descrito na portaria GM 336/02.

Atendimento intensivo: [...] oferecido quando a pessoa se encontra com grave sofrimento psíquico, em situação de crise ou dificuldades intensas no convívio social e familiar, precisando de atenção contínua. Esse atendimento pode ser domiciliar, se necessário; Atendimento semiintensivo: [...] é oferecido quando o sofrimento e a desestruturaçáo psíquica da pessoa diminuíram, melhorando as possibilidades de relacionamento, mas a pessoa ainda necessita 
de atenção direta da equipe para se estruturar e recuperar sua autonomia. Esse atendimento pode ser domiciliar, se necessário; Atendimento náo intensivo: oferecido quando a pessoa náo precisa de suporte contínuo da equipe para viver em seu território e realizar suas atividades na família e/ou no trabalho, podendo ser atendido até três dias no mês. Esse atendimento também pode ser domiciliar (BRASIL, 2004, p. 16).

Além disso, os CAPS devem prestar atenção de forma integrada à rede de serviços de saúde e de outros setores, a fim de oferecer o suporte necessário para a reinserção psicossocial das pessoas com transtornos mentais. As açôes desenvolvidas especificamente em seu território, ou seja, envolvendo as pessoas, os equipamentos sociais, os valores e a cultura presentes na área geográfica de abrangência do CAPS e na vida dos usuários, são também fundamentais para promoção da vida comunitária e para a garantia e estímulo à autonomia e à independência deles (BRASIL, 2004).

\section{Objetivo}

O objetivo deste trabalho foi relatar uma experiência de implantação e desenvolvimento de um Estágio Supervisionado em Terapia Ocupacional num Centro de Atenção Psicossocial - CAPS II, com estudantes do oitavo período do Curso de Terapia Ocupacional da Universidade Federal do Paraná (UFPR), numa modalidade de Estágio de Prática Autônoma, descrevendo as características e objetivos do equipamento e o processo de ensino e aprendizagem por meio da assistência aos usuários.

\section{Metodologia}

Este trabalho caracteriza-se pelo relato de experiência de um docente e um grupo de estagiários do oitavo período do curso de Graduação em Terapia Ocupacional da UFPR.

O grupo de estagiários ingressou em 2008 no curso em cuja grade curricular há uma disciplina denominada Estágio Supervisionado em Terapia Ocupacional - Prática III, que se caracteriza por ser uma prática autônoma ${ }^{1}$. Essa disciplina possui uma carga horária de 15 horas semanais, as quais se dividiam em três horas de supervisão e 12 horas em campo de prática.

No segundo semestre de 2011, tal turma iniciou a disciplina, sendo que uma equipe de cinco discentes ficou designada para a Área de Saúde Mental. Essa prática era dividida em: quatro horas semanais no Ambulatório de Saúde Mental do Hospital de Clínicas - UFPR e oito horas semanais em um CAPS II de Curitiba, sob supervisão semidireta ${ }^{2}$ do professor responsável.

Este trabalho trata especificamente da experiência do grupo no CAPS II. O horário para atendimento no CAPS foi ajustado de acordo com as necessidades do CAPS e também de acordo com as regras gerais de estágio, e os discentes permaneceram em dupla na maior parte dos atendimentos.

Essa foi a primeira equipe de estagiários desse CAPS. Realizou-se um período de observação e discussôes em supervisão e, ao final dessa primeira etapa, elaborou-se um relatório contendo os dados observados. Com base nessas informações foi construído um relatório com as características do serviço, o perfil dos usuários e, a partir daí, a proposta para a realizaçáo da intervenção de Terapia Ocupacional em cada um dos diferentes regimes.

$\mathrm{Na}$ instituição existia apenas uma profissional de Terapia Ocupacional. A portaria 224/92 estabelece que para hospitais psiquiátricos a proporção de terapeutas ocupacionais por pacientes deve ser de $1 / 60$, essa regra, no entanto, não se aplica aos CAPS (BRASIL, 1992). Acredita-se que esse seja um dos motivos pelo qual o programa de reinserçáo social acaba prejudicado, pois a capacidade laborativa do profissional é limitada e utilizada inteiramente na rotina interna.

Dessa maneira o grupo, composto por cinco estagiários, com a carga horária de oito horas semanais cada, orientados diretamente pela terapeuta ocupacional da instituição e supervisionados pelo docente, pôde propor um projeto que complementasse o trabalho de Terapia Ocupacional já existente.

Inicialmente ocorreu a observação do funcionamento institucional e o contato inicial com os usuários, sendo depois realizada uma entrevista com eles a fim de detectar suas necessidades para finalmente ocorrer a intervençáo e, posteriormente, a avaliaçáo de todo o processo, incluindo-se o processo de ensino-aprendizagem dos estudantes.

\section{Resultados}

\subsection{Observação institucional}

Durante o primeiro mês de estágio (agosto de 2011), a ação realizada foi basicamente a observação da rotina do CAPS e o acompanhamento das atividades desenvolvidas pelos usuários e pela equipe. 
O CAPS II em questáo é conveniado com a prefeitura municipal local e presta serviços a 220 usuários, encaminhados exclusivamente pelas Unidades de Saúde de dois Distritos Sanitários da cidade. Os atendimentos são ofertados em diferentes regimes, sendo eles: intensivo, semi-intensivo e não intensivo, nas modalidades individual e grupal, além de reunióes de família.

A equipe multidisciplinar desse CAPS é composta por profissionais das áreas de Psiquiatria, Psicologia, Terapia Ocupacional, Enfermagem, Serviço Social e outros profissionais de nível médio - auxiliares de enfermagem e oficineiros. Ainda conta com voluntários do serviço de Terapia Comunitária e uma artesã.

$\mathrm{Na}$ admissão dos usuários, o serviço de Terapia Ocupacional é responsável por realizar a avaliação do desempenho nas áreas de ocupação, planejar juntamente aos usuários a agenda de bolso (onde constam as atividades que serão realizadas nos dias em que frequentam o CAPS), auxiliando-os a engajarem-se em atividades ofertadas.

São funçôes do terapeuta ocupacional: coordenar e supervisionar os oficineiros nas oficinas de artesanato, lazer e culinária, coordenar os usuários que participam das diversas comissóes (recepção, limpeza e manutenção, jardinagem, dentre outras), planejar atividades de lazer externas ao CAPS, de acordo com o interesse dos usuários, elaborar pareceres para o processo de solicitação de concessão de benefícios previdenciários ${ }^{3}$, elaborar relatórios a serem apresentados nas reuniôes de distrito, realizar intervençôes individuais referentes, principalmente, ao desempenho ocupacional nas atividades de vida diária, atividades instrumentais de vida diária, trabalho, lazer e participação social, encaminhar usuários para cursos profissionalizantes no Liceu de Ofícios e realizar atendimentos em grupo.

Conforme esclarecido acima, a observação focou-se na rotina institucional e nas características dos usuários de cada um dos regimes.

\subsection{Características gerais dos usuários}

Durante o período de observação institucional, além das entrevistas, foram realizados contatos informais com os usuários e conversas ocasionais. Foram observadas características comuns, de acordo com o regime frequentado.

\subsubsection{Regime não intensivo}

Esses usuários frequentam o CAPS três vezes por mês. Observou-se que a mudança para o regime não intensivo geralmente acarreta perda do auxílio transporte e do benefício previdenciário concedidos pelos órgãos públicos. De acordo com relatos dos usuários, os peritos colocam em dúvida o fato de eles precisarem do benefício, devido a frequentarem o CAPS apenas três vezes ao mês. De acordo com relatos dos usuários, os peritos informam que para a concessão do benefício é necessário que frequentem o CAPS diariamente ou, no mínimo, três vezes por semana, no caso do benefício de transporte, dando a entender, nas entrelinhas, que quem frequenta o CAPS apenas três vezes por mês já deveria estar em condiçốes de voltar ao trabalho e que assim não necessitaria mais do benefício. Observou-se que a maioria dos usuários que frequenta esse regime permanece mais tempo no ambiente domiciliar e não está inserida em atividades sócio-ocupacionais fora do CAPS. Verbalizam claramente que desejam voltar a frequentar o regime semi-intensivo ou intensivo. Em geral, em função da possibilidade de recuperação dos benefícios perdidos e, muitas vezes, para minimizar o estresse acarretado pelo aumento de horas passadas no convívio familiar. Não foi possível perceber perspectivas positivas relatadas por esses usuários em função de seu presumido progresso no tratamento.

Por esse motivo foi proposto em um primeiro momento realizar-se entrevista e avaliação ocupacional para verificar a rotina desses usuários e identificar quais atividades eles realizavam e em quais apresentavam dificuldades. Em um segundo momento seria realizado um grupo semanal de orientação e acompanhamento para discussão acerca da inserção sócio-ocupacional em projetos, atividades ou ocupaçóes na comunidade, e, principalmente, estimular a participação em atividades e ocupaçôes no território. O objetivo seria discutir com o usuário as vantagens que ele teria em resgatar ou construir sua própria autonomia, por meio do envolvimento em ocupaçôes significativas e participação social.

\subsubsection{Regime semi-intensivo}

Observou-se que nesse regime há dificuldades quanto ao estabelecimento de rotina, tanto dentro quanto fora do CAPS. Acredita-se que essa dificuldade esteja relacionada à maior necessidade de apoio aos usuários para que eles construam sua rotina de atividades fora do CAPS. A ideia inicial foi auxiliar intensivamente esses usuários na construção de uma rotina fora do ambiente clínico/institucional, com o objetivo de prepará-los para o regime náo intensivo, de forma que tenham vontade de ficar mais tempo fora do CAPS e de envolverem-se em ocupaçóes significativas em outros ambientes, percebendo quais seriam as vantagens e os ganhos. 


\subsubsection{Regime intensivo}

Quanto ao regime intensivo, observou-se que a rotina dos usuários parece estar organizada em torno de sua participação no CAPS. O envolvimento em ocupações que podem ser significativas ou não e a participação social, por parte dos usuários, está restrita ao CAPS, na maioria dos casos. Por esse motivo, acredita-se que os usuários sejam dependentes de incentivo da equipe e da organizaçáo institucional para desempenhar certas atividades. Sendo assim, pareceu necessário fomentar a vontade e a descoberta de interesses desses usuários.

\subsection{Perfil dos usuários}

A entrevista inicial abrangeu, além dos dados sociodemográficos, aspectos da vida ocupacional dos usuários e foi baseada nas áreas de ocupação e nos subsistemas apresentados pelo Modelo da Ocupação Humana. Ela foi realizada com aproximadamente $65 \%$ dos usuários que frequentavam o CAPS e ocorreu durante os meses de setembro e outubro de 2011; foi composta por questôes que buscavam informaçóes gerais dos usuários, como: nome, data de nascimento, sexo, endereço, estado civil, bairro no qual reside e a Unidade Básica de Saúde pela qual foi encaminhado. Continha informaçóes referentes à saúde, como: diagnóstico, medicamentos utilizados, doenças preexistentes e informaçôes sobre os internamentos ocorridos. Também foram coletadas informaçôes sobre a situação funcional, como: escolaridade, profissão, trabalhos e empregos, e a situaçáo junto ao INSS e sobre o tempo de permanência no CAPS, tempo de tratamento, regime de tratamento ao qual pertence no CAPS, dias da semana em que frequenta o CAPS e quais as atividades que realizavam na instituição. Além de informaçôes da vida ocupacional, como: quais atividades realizavam, dividindo-as em atividades de vida diária, produtivas e de lazer; questionou-se sobre a existência da vontade de retomar a realização de alguma atividade em sua vida ou se há a vontade de iniciar tal realização. Por fim, na entrevista, havia espaço destinado a anotaçóes que o estagiário considerasse relevante constar em tal documento. Embora muitas dessas informaçóes estivessem disponíveis nos prontuários, considerou-se importante o contato pessoal do estagiário, para que tomasse conhecimento das mesmas por intermédio do próprio usuário, como oportunidade para conhecê-lo pessoalmente, saber sua opiniáo sobre os fatos ocorridos em sua vida e iniciar o processo de formaçáo do vínculo.

A partir da coleta de dados foi construído o perfil dos usuários dos diferentes regimes de atendimento (Tabela 1).
Nos três regimes, a maioria é do sexo feminino, sem companheiros(as) (solteiras, divorciadas e viúvas), com primeiro grau ou ensino fundamental incompleto, afastada do trabalho por doença, idade média de 45 anos e morando com a família.

A grande maioria (85\%) participa de alguma das atividades do CAPS (Figura 1), podendo-se inferir que o ambiente do CAPS estimula a participação em atividades.

Já com relação à participação em atividades fora do CAPS (Figura 2), as respostas caem quase que pela metade, sendo possível inferir que há maior dificuldade de o usuário se inserir em atividades fora do CAPS, como em atividades de lazer, de trabalho, produtivas e até mesmo desenvolver as atividades de vida diária.

Quando questionados sobre de qual atividade mais sentiam falta, o maior número de respostas dos três regimes foi trabalho (Figura 3).

\subsection{Plano de ação e intervenção}

Considerando-se as informaçôes acima citadas, os usuários foram divididos em grupos conforme o regime de tratamento no CAPS (intensivo, semiintensivo e não intensivo) para fins do atendimento de Terapia Ocupacional a ser realizado pelo grupo de estagiários. Tomou-se por base o fato de que cada um dos regimes abriga usuários com necessidades e características específicas.

A avaliação ocorreu de forma constante, desde os primeiros contatos realizados informalmente, passando pelas entrevistas e prosseguindo com a análise dos relatos dos usuários sobre seu cotidiano.

O processo terapêutico privilegiou os atendimentos grupais, baseado em avaliações e orientações e ou assessorias no próprio grupo. As principais demandas foram: a falta de uma rotina dos usuários fora do CAPS; a dependência da instituição; a ausência ou diminuição da volição dos usuários para iniciar ou retomar atividades; e a falta de interesses. Nesse âmbito, foram estabelecidos como objetivos dos atendimentos grupais: acompanhar a vida ocupacional dos usuários por meio de seus relatos sobre o cotidiano; estimular a ampliaçáo da vida ocupacional e a retomada de ocupaçóes significativas; explorar e fomentar a voliçáo e a busca de interesses; e estimular a reinserção social desses usuários em seu território.

Foram estimuladas habilidades de comunicação e interação (KIELHOFNER, 2008a). Discutiram-se questóes relacionadas ao controle social e a açóes para informação e minimizaçáo do preconceito da comunidade em relação ao estigma acerca das pessoas com transtornos mentais. 
Tabela 1. Perfil sociodemográfico.

\begin{tabular}{|c|c|c|c|c|c|c|}
\hline \multirow{2}{*}{$\begin{array}{l}\text { Sexo } \\
\end{array}$} & \multicolumn{2}{|c|}{ Intensivo } & \multicolumn{2}{|c|}{ Semi-intensivo } & \multicolumn{2}{|c|}{ Não intensivo } \\
\hline & & & & & & \\
\hline Feminino & 21 & $57 \%$ & 34 & $57 \%$ & 31 & $65 \%$ \\
\hline Masculino & 16 & $43 \%$ & 26 & $43 \%$ & 17 & $35 \%$ \\
\hline \multicolumn{7}{|l|}{ Estado civil } \\
\hline Solteiro(a) & 10 & $27 \%$ & 14 & $23 \%$ & 12 & $25 \%$ \\
\hline Casado(a) & 16 & $43 \%$ & 36 & $60 \%$ & 22 & $46 \%$ \\
\hline Divorciado(a) & 9 & $24 \%$ & 7 & $12 \%$ & 13 & $27 \%$ \\
\hline Viúvo(a) & 2 & $5 \%$ & 3 & $5 \%$ & 1 & $2 \%$ \\
\hline \multicolumn{7}{|l|}{ Nível educacional } \\
\hline Analfabeto & 3 & $8 \%$ & 3 & $5 \%$ & 1 & $2 \%$ \\
\hline $1^{\circ} \mathrm{Grau}$ incompleto & 14 & $38 \%$ & 18 & $30 \%$ & 17 & $35 \%$ \\
\hline $1^{\circ}$ Grau completo & 05 & $14 \%$ & 10 & $16 \%$ & 13 & $27 \%$ \\
\hline $2^{\circ} \mathrm{Grau}$ incompleto & 3 & $8 \%$ & 8 & $13 \%$ & 5 & $10 \%$ \\
\hline $2^{\circ}$ Grau completo & 7 & $19 \%$ & 19 & $31 \%$ & 10 & $21 \%$ \\
\hline Superior incompleto & 1 & $3 \%$ & 1 & $1 \%$ & 1 & $2 \%$ \\
\hline Superior completo & 2 & $5 \%$ & 1 & $1 \%$ & 0 & $0 \%$ \\
\hline Não relatou & 2 & $5 \%$ & 0 & $0 \%$ & 1 & $2 \%$ \\
\hline \multicolumn{7}{|l|}{ Situação funcional } \\
\hline Afastado por doença & 20 & $54 \%$ & 47 & $78 \%$ & 23 & $48 \%$ \\
\hline Aposentado por invalidez & 5 & $14 \%$ & 6 & $10 \%$ & 10 & $21 \%$ \\
\hline Ativo & 0 & $0 \%$ & 3 & $5 \%$ & 1 & $2 \%$ \\
\hline Inativo & 12 & $32 \%$ & 3 & $5 \%$ & 14 & $29 \%$ \\
\hline Não respondeu & 0 & $0 \%$ & 1 & $3 \%$ & 0 & $0 \%$ \\
\hline Média de idade (anos) & & 43 & & 45 & & 47 \\
\hline \multicolumn{7}{|l|}{ Com quem mora } \\
\hline Sozinho & 2 & $5 \%$ & 9 & $15 \%$ & 5 & $10 \%$ \\
\hline Família & 35 & $95 \%$ & 50 & $83 \%$ & 43 & $90 \%$ \\
\hline Outra pessoa & 0 & $0 \%$ & 1 & $2 \%$ & 0 & $0 \%$ \\
\hline
\end{tabular}

Fonte: Elaborado pelos autores.

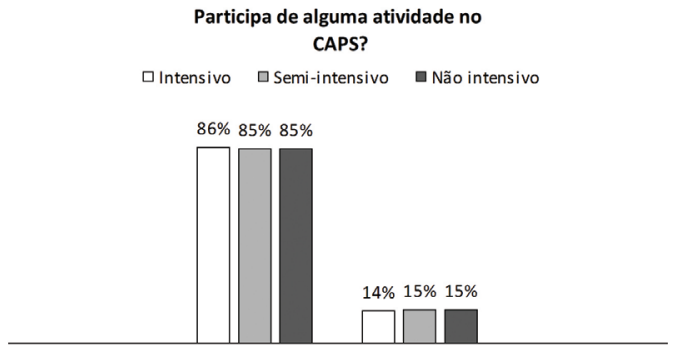

$\operatorname{sim}$

Não

Figura 1 . Participação em atividades no CAPS. Fonte: Elaborado pelos autores.

Buscou-se também estimular interesses e vontades, valorizando-se o significado das atividades e o próprio desempenho dos usuários nelas.

Estimulou-se ainda a resolução de problemas por meio da reflexão sobre as dificuldades encontradas no desempenho das ocupaçóes, em especial naquelas ligadas à interação com outras pessoas.

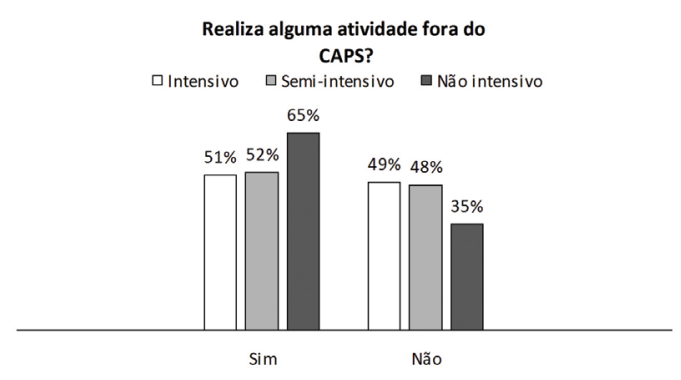

Figura 2. Participação em atividades fora do CAPS. Fonte: Elaborado pelos autores.

Além disso, iniciou-se junto aos usuários a reflexão sobre a função do CAPS e instigou-se a desconstrução da concepção institucionalizada de atenção em Saúde Mental, estimulando-se, assim, a reflexão sobre um tratamento inclusivo e participativo, no qual o indivíduo participa de atividades comunitárias e utiliza os equipamentos sociais do seu território; 


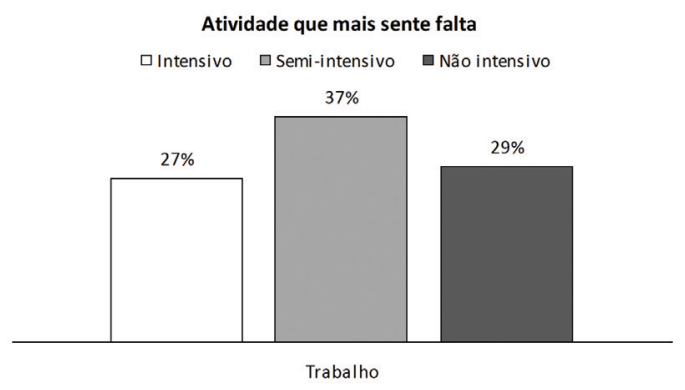

Figura 3. Atividades de que mais sentem falta. Fonte: Elaborado pelos autores.

além de ter o poder de modificar o sistema e as políticas por meio do seu engajamento em açóes representativas e na busca por seus direitos, pela melhoria da qualidade dos serviços, ou seja, como cidadão engajado no controle social de seus direitos, açôes que, de acordo com Saraceno (1998), seriam os verdadeiros objetivos da reabilitação psicossocial.

Embora o vínculo e a tutela proporcionados pelo CAPS ao usuário sejam muitas vezes importantes para a retomada da participação ocupacional e social dele, é necessário evitar que o usuário passe a se limitar às relaçôes e ao desempenho de atividades apenas no CAPS.

Nesse âmbito, o serviço substitutivo como proposto na reforma psiquiátrica deveria dar conta de possibilitar a formação de uma nova rede de suporte social e comunitária, para que o usuário tivesse sua participação ocupacional e social garantida.

Foram realizadas ainda orientaçóes voltadas às áreas de desempenho de atividades de vida diária (principalmente autocuidado e rotina de medicação), produtivas (em especial limpeza da casa, cuidados com a alimentaçấo e vestuário) e de trabalho e de lazer.

Quanto ao modelo de prática, foram utilizados conceitos do Modelo de Ocupação Humana na caracterizaçáo dos problemas de desempenho ocupacional. Desse modo considerou-se que os problemas de desempenho ocupacional dos sujeitos atendidos no CAPS são provenientes de problemas nos subsistemas de volição (vontade, interesses, motivação e significados para o desempenho de ocupaçốes), de habituação (falta de hábitos e rotinas, ou rotinas ligadas estritamente à dinâmica do CAPS) e de habilidades de desempenho (habilidades de processo, sociais e de interação), em relaçáo com o ambiente no qual está inserido (favorecedor ou não para o desempenho) (KIELHOFNER, 2008b).

No âmbito cognitivo-comportamental, os usuários foram estimulados a refletirem sobre seus pensamentos, sentimentos e atitudes e sobre sua influência no desempenho ocupacional. Além disso, estimulou-se a resolução de problemas e o estabelecimento de metas pelos próprios usuários, a fim de minimizar ou solucionar as dificuldades de desempenho.

O trabalho grupal foi bastante utilizado, a fim de proporcionar um espaço de troca de experiências e resoluçáo de problemas, de modo a favorecer a comunicaçáo e a expressão de interesses, vontades e dificuldades de desempenho (HAGEDORN, 2001).

Por fim, em relação aos processos de mudança, as ações empregadas no CAPS estimularam os processos de educação, reabilitação e adaptação.

O processo de educação foi desenvolvido nos grupos pelo aumento do conhecimento dos usuários, pelo estímulo e aprimoramento de habilidades dos usuários e pela adequação e estímulo à mudança de atitude frente ao transtorno mental, a si mesmo e à sociedade. Já o processo de reabilitação foi desenvolvido especificamente no âmbito da reabilitação psicossocial, com vistas ao engajamento dos usuários em ocupaçóes significativas, ao aumento ou retomada de sua autonomia e independência e, consequentemente à sua reinserção social (SARACENO, 1998).

O processo de adaptação, por sua vez, esteve voltado à adaptação das ocupações, com o fracionamento das atividades para facilitar o desempenho de tarefas completas (HAGEDORN, 2001).

Não foi possível a realização de uma reavaliação formal. Pode-se afirmar, no entanto, como resultados parciais baseados nos relatos dos usuários, que os atendimentos grupais possibilitaram: o aumento da autopercepção e reflexão deles em relação às suas açóes e posturas frente ao transtorno mental; o compartilhamento de experiências e, consequentemente, o estímulo mútuo ao desempenho ocupacional fomentado entre os próprios usuários; a expressão de interesses e a iniciativa em buscar novos papéis devido ao suporte oferecido pelo grupo; a facilitaçáo da resoluçáo de problemas relacionados ao desempenho ocupacional; e o estímulo à atuação como cidadão fora da instituição.

\section{Discussão}

Inicialmente acreditou-se que os estagiários pudessem concentrar seu trabalho especialmente junto aos usuários do regime não intensivo, por serem os que frequentam o CAPS o menor número de vezes por mês (três) e que, teoricamente, fossem talvez o grupo que mais necessitasse de auxílio e 
estivesse mais pronto para sua inserção psicossocial. No entanto, essa linha de raciocínio foi modificada quando do contato com a realidade, na qual se perceberam as características já citadas, tais como o desejo e a necessidade de esses usuários retornarem para o regime semi-intensivo ou para o intensivo, para tentarem retomar direitos básicos de auxílio-doença e transporte, perdidos com sua suposta "ascensão" para o regime náo intensivo, no qual se pressupóe melhora no estado geral de saúde.

Dessa maneira percebe-se que há uma grande contradição no sistema, pois na medida em que o indivíduo melhora sua saúde e que poderia caminhar em direção à alta do CAPS ele, ao invés de receber incentivos, recebe "puniçôes", tais como as já citadas perdas do auxílio-doença e auxílio transporte. Isso é claramente um reforço negativo para a melhora da saúde da pessoa, chegando ao absurdo de criar situaçôes nas quais as pessoas manifestam explicitamente seu desejo de não melhorar ou até mesmo de piorar, pois não podem ficar sem o dinheiro do auxílio-doença que, muitas vezes, é o que garante seu sustento e até o de outras pessoas da família dele, que são seus dependentes. Essa contradição coloca os profissionais da saúde mental e especialmente o Terapeuta Ocupacional numa situação de impotência. Como e porque incentivar uma pessoa a ter autonomia e independência em suas atividades e ocupaçôes se ela receberá por isso uma punição? Sim, porque todos sabem que para uma pessoa com transtorno mental conseguir um trabalho formal remunerado e mantê-lo com as exigências competitivas do mercado de trabalho não faz parte de nossa realidade. Percebe-se aqui a importância da compreensão de um outro conceito defendido por Saraceno (1998), que diz que a reabilitação psicossocial nos permite romper com a perigosa separação entre sujeito e contexto. De fato, isso fica bastante evidenciado na prática, o sujeito está totalmente dependente de seu contexto. Em outros países, como no Canadá, por exemplo, sabe-se que existem centros de reabilitaçáo profissional, ou centros de trabalho protegido onde as pessoas recebem remuneração pelo seu desempenho produtivo, sendo consideradas suas capacidades e limitações. No Brasil precisamos caminhar para um modelo que garanta a subsistência da pessoa, caso queiramos ter sucesso em nosso trabalho como terapeutas ocupacionais. Caso contrário estaremos fadados ao fracasso, juntamente com o CAPS e o modelo de saúde mental aplicado. Certamente, esse não é um problema específico da Terapia Ocupacional, mas sim do modelo econômico social vigente em nosso e em muitos outros países. Em nossa sociedade, onde os direitos básicos, fundamentais, ainda não são garantidos para todos, observa-se a clara interlocuçáo entre os aspectos de saúde e os sociais. Se o usuário recebe alta, ele deixa de receber o benefício previdenciário que garante sua subsistência.

Do ponto de vista da Terapia Ocupacional, especificamente do ponto de vista do Modelo da Ocupação Humana, parece que nossos usuários dos CAPS estão num ciclo malévolo, onde sua natureza ocupacional não está em pleno funcionamento (KIELHOFNER, 2008c, d, e), encontrando-se essa assistência em condiçôes bastante precárias de funcionamento. Essa condição poderia ser classificada até mesmo como de privação ocupacional. A privação ocupacional se daria não apenas pela restrição de liberdade de ir e vir (TOWNSEND, 2002), mas pela restrição do incentivo à participação em ocupaçóes significativas, ou até mesmo pela punição. $\mathrm{O}$ indivíduo que vier a trabalhar ou mesmo ensaiar um trabalho por meio de atividades produtivas informais está sujeito à perda do benefício previdenciário. Novamente aqui destacamos a importância do contexto.

Concordamos com Saraceno (2011) quando afirma que aqueles que sofrem de doença mental são expostos a violaçôes dos direitos humanos e de cidadania.

Com relação às características do serviço, conforme já afirmado anteriormente, o que ocorre é que a equipe possui limitaçóes para o desenvolvimento de atividades fora do CAPS, seja por motivo de sobrecarga de trabalho, ou por déficit na formação para o trabalho com as atuais diretrizes em saúde mental. Algumas atividades externas são desenvolvidas, mas conforme afirma Fiorati e Saeki (2012, p. 212),

[...] essa atividade externa para por aí e não se buscam mais inserçóes efetivas no social, e as atividades são desenvolvidas preferencialmente nos serviços, com poucas incursóes para o território.

As intervençôes no território foram pensadas e planejadas para serem executadas gradualmente. Esse CAPS atende a usuários de aproximadamente nove bairros. Dessa forma, foi planejado um levantamento dos recursos comunitários de cada um desses bairros e o levantamento dos usuários que neles residiam. Além disso, pensou-se em atividades externas que pudessem ser desenvolvidas no território do CAPS, como por exemplo caminhadas e jogos em uma quadra poliesportiva localizada nas proximidades.

O serviço de saúde mental é comunitário não porque está situado (isto é, tem um endereço postal) em certo lugar de uma cidade ou de 
uma zona rural. Ser comunitário implica uma estratégia de açóes e interaçóes com a comunidade. [...] A comunidade é, em si, um recurso, os organismos públicos (os outros serviços sanitários, as escolas, as entidades assistenciais) e aqueles privados (as paróquias, os partidos políticos, os sindicatos, as associaçóes esportivas etc.) são, todos, recursos (SARACENO, 2011, p. 99-100).

Essa afirmação de Saraceno ilustra o longo caminho que ainda se tem por percorrer, pois as equipes dos CAPS possuem ainda muita dificuldade para sair ao encontro com a comunidade. Acreditamos que, em parte, por dificuldades reais em relação à sobrecarga de trabalho e, em parte, pelas deficiências na formação para o trabalho, aspecto para o qual o estágio também poderá contribuir.

Com relação ao ensino-aprendizagem do grupo de estudantes, a discussão semanal entre grupo e supervisor, avaliando e considerando todos os aspectos apontados, promoveu o desenvolvimento profissional, no sentido de compreenderem a realidade e as limitaçóes impostas por nosso sistema de saúde, pelas características do serviço, pelo sistema socioeconômico e cultural, assim como as possibilidades e caminhos para a superação e aperfeiçoamento, especialmente por meio da participação na construção das políticas públicas e por meio do aperfeiçoamento do serviço. De acordo com Saraceno (1998), a reabilitação psicossocial é uma estratégia que promove as relaçóes e torna possível que a experiência do sofrimento psíquico do sujeito não o invalide, possibilitando a recuperação de sua capacidade de gerar sentido e valor social e restabelecendo sua contratualidade como cidadão.

\section{Considerações finais}

O estágio supervisionado em Terapia Ocupacional na modalidade de prática autônoma possibilitou aos estudantes o contato direto com a realidade, o conhecimento do funcionamento do sistema de saúde, das características do serviço, com suas limitaçóes e contradiçóes, e a aproximação com os usuários, no sentido de perceber sua realidade, suas condiçôes socioeconômicas e familiares, seus desejos e aspiraçóes, assim como a falta deles. As dificuldades para o engajamento desses usuários em ocupaçóes significativas em seu próprio território e as limitaçóes e estigmas a eles impostos pela sociedade, assim como a reflexão sobre as influências do sistema socioeconômico vigente e sobre a necessidade de se repensarem os serviços existentes e ofertados. Essa é uma etapa bastante importante do aprendizado, pois é possível trabalhar as frustraçóes e a percepçáo de que a única maneira de mudar a realidade, além da prática clínica ampliada, que ainda assim apresenta inúmeras limitaçóes, é por meio da participação na discussão e formulação das políticas públicas de assistência à saúde mental, da constante avaliação e reformulação dos serviços oferecidos e do controle social.

\section{Referências}

BRASIL. Ministério da Saúde. Portaria no 224, de 29 de janeiro de 1992. Diário Oficial [da] República Federativa do Brasil, Poder Executivo, Brasília, DF, 29 jan. 1992.

BRASIL. Ministério da Saúde. Portaria no 336, de 19 de fevereiro de 2002. Diário Oficial [da] República Federativa do Brasil, Poder Executivo, Brasília, DF, 19 fev. 2002.

BRASIL. Ministério da Saúde. Secretaria de Atenção à Saúde. Departamento de Ações Programáticas Estratégicas. Saúde mental no SUS: os centros de atenção psicossocial. Brasília: Ministério da Saúde, 2004. (Série F. Comunicação e Educação em Saúde).

FIORATI, R. C.; SAEKI, T. As atividades terapêuticas em dois serviços extra hospitalares de saúde mental: a inserção das ações psicossociais. Cadernos de Terapia Ocupacional da UFSCar, São Carlos, v. 20, n. 2, p. 207-215, 2012.

HAGEDORN, R. Fundamentos da prática em Terapia Ocupacional. São Paulo: Dynamis, 2001.

HIRDES, A. A reforma psiquiátrica no Brasil: uma (re) visão. Ciência e Saúde Coletiva, Rio de Janeiro, v. 14, n. 1, p. 297-305, 2009.

KIELHOFNER, G. Dimensions of doing. In: KIELHOFNER, G. Model of human occupation: theory and application. 4. ed. Baltimore: Lippincott Williams \& Wilkins, 2008a. p. 101-109.

KIELHOFNER, G. The basic concepts of human occupation. In: KIELHOFNER, G. Model of human occupation: theory and application. 4. ed. Baltimore: Lippincott Williams \& Wilkins, 2008b. p. 11-23.

KIELHOFNER, G. Introduction to the model of human occupation. In: KIELHOFNER, G. Model of human occupation: theory and application. 4. ed. Baltimore: Lippincott Williams \& Wilkins, 2008c. p. 1-7.

KIELHOFNER, G. The dynamics of human occupation. In: KIELHOFNER, G. Model of human occupation: theory and application. 4. ed. Baltimore: Lippincott Williams \& Wilkins, 2008d. p. 24-31.

KIELHOFNER, G. Habituation: patterns of daily occupation. In: KIELHOFNER, G. Model of human occupation: theory and application. 4. ed. Baltimore: Lippincott Williams \& Wilkins, 2008e. p. 51-67.

IBRAHIM, F. Z. Curso de direito previdenciário. Rio de Janeiro: Impetus, 2009.

SARACENO, B. A concepção de reabilitação psicossocial como referencial para as intervençóes terapêuticas em Saúde Mental. Revista de Terapia Ocupacional, São Paulo, v. 9, n. 1, p. 26-31, 1998. 
SARACENO, B. A cidadania como forma de tolerância.

Revista de Terapia Ocupacional, São Paulo, v. 22, n. 2, p. 93-101, 2011.

TOWNSEND, E. Enabling occupation: an occupational therapy perspective. Ottawa: CAOT Publications, 2002.
UNIVERSIDADE FEDERAL DO PARANÁ - UFPR.

Projeto pedagógico do curso de Terapia Ocupacional. Curitiba: UFPR, 2010a.

UNIVERSIDADE FEDERAL DO PARANÁ - UFPR. Conselho de Ensino, Pesquisa e Extensão. Resolução no 46/10-CEPE. Dispóe sobre os estágios na Universidade Federal do Paraná. Curitiba, 6 ago. 2010b.

\section{Contribuição dos Autores}

Mariotti, Milton Carlos: Concepção do artigo, orientação, supervisão e revisão do texto. Marques, Luciana Carvalho; Schlean, Aline; Silva, Rafaela; e Stoffel, Diane Priscila: Estagiárias, coleta de dados e colaboração na elaboração do texto. Veiga, Bruna: Terapeuta ocupacional - CAPs II, preceptora de estágio, colaboração na elaboração do texto.

\section{Notas}

${ }^{1}$ Prática autônoma, de acordo com a definição do projeto pedagógico do curso, é aquela que ocorre nos dois últimos períodos do curso, quando se considera que o estudante já tenha conquistado habilidades de autonomia para a tomada de decisões e resolução de problemas (UNIVERSIDADE..., 2010a).

${ }^{2}$ Supervisão semidireta é o tipo de supervisão na qual o docente não está presente em toda a carga horária no local do estágio. O estagiário está sob orientação do profissional da instituição e a supervisão ocorre em $10 \%$ da carga horária (resolução 46/10-UFPR) (UNIVERSIDADE..., 2010b).

${ }^{3}$ Benefícios: É um sistema de proteção social que assegura o sustento do trabalhador e de sua família quando ele não pode trabalhar por causa de doença, acidente, gravidez, prisão, morte ou velhice (IBRAHIM 2009). 